outcomes and medication adherence in difficult-to-control asthma. Thorax 2012; 67(8):751-53. http://dx.doi.org/10.1136/thoraxjnl-2011-201096

7. Clatworthy J, Price D, Ryan D, Haughney J, Horne R. The value of self-report assessment of adherence, rhinitis and smoking in relation to asthma control. Prim Care Respir J 2009;18(4):300-05. http://dx.doi.org/10.4104/pcrj.2009.00037

8. Haynes RB, Yao X, Degani A, Kripalani S, Garg AX, McDonald HP. Interventions for enhancing medication adherence. Cochrane Database of Systematic Reviews 2005(4):CD000011

9. Haynes RB, McDonald H, Garg AX, Montague P. Interventions for helping patients to follow prescriptions for medications. Cochrane Database of Systematic Reviews 2002(2):CD000011

10. Horne R. Compliance, adherence, and concordance: implications for asthma treatment. Chest 2006;130(1 Suppl):65S-72S doi: 130/1_suppl/65S

11. Price $D$, Lee $A J$, Sims EJ et al. Characteristics of patients preferring once-daily controller therapy for asthma and COPD: a retrospective cohort study. Prim Care Respir J 2013;22(2):161-8. http://dx.doi.org/10.4104/pcrj.2013.00017

12. Halm EA, Mora $P$, Leventhal $H$. No symptoms, no asthma: the acute episodic disease belief is associated with poor self-management among inner-city adults with persistent asthma. Chest 2006;129(3):573-80.

http://dx.doi.org/129/3/573[pii]

13. Horne $R$, Weinman J. Self-regulation and self-management in asthma: exploring the role of illness perceptions and treatment beliefs in explaining non-adherence to preventer medication. Psychology \& Health 2002;17(1):17-32.

http://dx.doi.org/10.1080/08870440290001502

\title{
Assessment of COPD in primary care: new evidence supports use of the DOSE index
}

\section{See linked article by Rolink et al. on pg 169}

\section{Josefin Sundh', Scott Montgomery², Björn Ställberg ${ }^{3}$, Karin Lisspers ${ }^{4}$}

1 Consultant Physician of Pulmonology, Department of Respiratory Medicine, Örebro University Hospital \& School of Health and Medical Science, Örebro University, Örebro, Sweden

2 Professor of Clinical Epidemiology, Department of Clinical Epidemiology and Biostatistics, Örebro University Hospital \& School of Health and Medical Science, Örebro University, Örebro, Sweden; and Clinical Epidemiology Unit, Department of Medicine, Karolinska University Hospital, Karolinska Institute, Stockholm, Sweden

3 Associate Professor and General Practitioner, Department of Public Health and Caring Science, Family Medicine and Preventive Medicine, Uppsala University, Uppsala, Sweden

4 Associate Researcher and General Practitioner, Department of Public Health and Caring Science, Family Medicine and Preventive Medicine, Uppsala University, Uppsala, Sweden

*Correspondence: Dr Josefin Sundh, Department of Respiratory Medicine, Örebro University Hospital, School of Health and Medical Science, Örebro University, 70185 Örebro, Sweden Tel: +46196025597, +46702349517, Fax: +46196021865 E-mail: josefin.sundh@orebroll.se

Recent modifications of the GOLD recommendations emphasise the importance of assessing symptoms or health status, in addition to lung function and exacerbation frequency, in order to produce a more comprehensive view of the COPD patient. ${ }^{1}$ There is, however, a difficult challenge in finding a convenient way of evaluating COPD in primary care where the majority of COPD patients are managed. In fact, the usefulness of the new GOLD categories in primary care has been debated. ${ }^{2}$

The article by Rolink and colleagues ${ }^{3}$ in this issue of the PCRJ shows that the recently described DOSE index is predictive of change in health status measured by the Clinical COPD Questionnaire (CCQ). This finding increases the potential value of the DOSE index, which has already demonstrated its clinical usefulness.

The MRC scale is a well-known instrument for estimating the important symptom of dyspnoea due to physical activity in COPD patients. In a study from 2002, the MRC scale was shown to be a more effective predictor of mortality than lung function in COPD. ${ }^{4}$ However, the multisystem complexity of COPD has resulted in a requirement for comprehensive instruments that can take into account several aspects of the disease. The term health status covers not only symptoms but the broader influence of disease on daily activities and wellbeing. ${ }^{5}$ The St George's Respiratory Questionnaire (SGRQ), a disease-specific instrument originally developed to evaluate health status, ${ }^{6}$ is often used in clinical trials as a gold standard for evaluating health-related quality of life (HRQL) in respiratory diseases. As HRQL reflects the general impact of a disease on a patient's wellbeing, the terms HRQL and health status are very closely related and often used synonymously.

However, the SGRQ is an extensive instrument that can be timeconsuming to complete, making it inconvenient to use in clinical practice. More recently, shorter instruments have been developed. In 2005, the CCQ was introduced as a convenient instrument for measurement of health status; it includes ten items about symptoms, emotional dysfunction and limitations of physical activity. ${ }^{7}$ It correlates well with the SGRQ, with the Chronic Respiratory Questionnaire (CRQ), and the generic instrument Short form-36 (SF-36), ${ }^{7,8}$ and is practical to use in primary care. ${ }^{9}$ In 2009, the COPD Assessment Test (CAT) was developed, and this includes eight items on symptoms, activities and other impacts of COPD on health status. ${ }^{10}$ In the most recent GOLD update, both the CAT and CCQ scores are recommended for clinical evaluation of health status in COPD patients. $^{1}$

In primary care, there is clearly a need for simple tools which can present as much clinically relevant information on the disease as efficiently as possible. Jones and colleagues developed the Dyspnoea, Obstruction, Smoking and Exacerbation (DOSE) index with a view to combining information relevant for both clinical management and assessment of disease severity. ${ }^{11}$ Other multidimensional instruments, like the BODE index (BMI, Obstruction, Dyspnoea and Exercise capacity ${ }^{12}$ and the ADO index (Age, Dyspnoea and Obstruction), ${ }_{13}^{13}$ also 
have the advantage of reflecting several aspects of COPD. However, the BODE index includes the Six Minute Walking Distance test for measuring exercise capacity, which limits its practicality for use in primary care. The DOSE index includes clinically relevant and easily collected information, and importantly, several of its measurable components can be modified by interventions, which is an advantage in comparison with the ADO index.

Previously the DOSE index has been shown to predict the risk of exacerbations, hospital admissions, respiratory failure and mortality. ${ }^{11,14,15}$ Rolink and colleagues have now shown that the DOSE index is also able to predict changes in health status as measured by the CCQ. ${ }^{3}$ In a study population of 209 patients, with $54 \%$ from primary care, a DOSE index score of $\geq 4$ was a statistically significant predictor of clinically significant worsening in CCQ score over a twoyear follow-up period. Stratification by level of care revealed that the instrument was most predictive among primary care patients. This association has not previously been shown in a prospective study. Interestingly, a comparison with $\mathrm{FEV}_{1} \%$ predicted showed that the lung function component alone was not significantly associated with either change in CCQ or referral to secondary care. The study is well designed, with strengths including lung function data on all patients - which is not always possible in clinical COPD research - and statistical modelling that examines the degree of change during follow-up while taking into account baseline values.

These results emphasize the clinical usefulness of the DOSE index in primary care. We fully agree with the authors' remarks about the importance of future research focusing on prevention of health status deterioration among high-risk individuals.

Assessment of COPD should include clinically relevant measures that can be influenced by intervention, and also information on the risk of future health status deterioration and mortality. The present study by Rolink et al. ${ }^{3}$ adds important evidence that the DOSE index predicts change in health status. The DOSE index appears to combine all the required aspects and is also convenient to administer. Its use in the clinical management of COPD patients is very appealing, particularly in primary care.

Conflicts of interest The authors declare that they have no conflicts of interest in relation to this article. BS is an Associate Editor of the PCRJ, but was not involved in the editorial review of, nor the decision to publish, this article. JS, SM and $\mathrm{KL}$ have no conflicts of interest in relation to this article.

Commissioned article; not externally peer-reviewed; accepted 7th May 2013; online 24th May 2013

(c) 2013 Primary Care Respiratory Society UK. All rights reserved http://dx.doi.org/10.4104/pcrj.2013.00050

Prim Care Respir J 2013; 22(2): 142-143

\section{References}

1. Global Initiative for Chronic Obstructive Lung Disease. Global strategy for diagnosis, management, and prevention of COPD 2001 [updated 2013; cited 2013 25th March]; Available from: http://www.goldcopd.com.

2. Jones R, Price D, Chavannes N, et al. GOLD COPD categories are not fit for purpose in primary care. Lancet Respir Med 2013;1(1):e17.

3. Rolink M, van Dijk W, van den Haak-Rongen S, Pieters W, Schermer T, van den Bemt L. Using the DOSE index to predict changes in health status of patients with COPD: a prospective cohort study. Prim Care Respir J 2013;22(2):169-74. http://dx.doi.org/10.4104/pcrj.2013.00033

4. Nishimura K, Izumi T, Tsukino M, Oga T. Dyspnea is a better predictor of 5-year survival than airway obstruction in patients with COPD. Chest 2002;121(5):143440. http://dx.doi.org/10.1378/chest.121.5.1434

5. Curtis JR, Martin DP, Martin TR. Patient-assessed health outcomes in chronic lung disease: what are they, how do they help us, and where do we go from here? Am J Respir Crit Care Med 1997;156(4 Pt 1):1032-9. http://dx.doi.org/10.1164/ajrccm.156.4.97-02011

6. Jones PW, Quirk FH, Baveystock CM, Littlejohns P. A self-complete measure of health status for chronic airflow limitation. The St. George's Respiratory Questionnaire. Am Rev Respir Dis 1992;145(6):1321-7. http://dx.doi.org/10.1164/ajrccm/145.6.1321

7. van der Molen T, Willemse BW, Schokker S, ten Hacken NH, Postma DS, Juniper EF Development, validity and responsiveness of the Clinical COPD Questionnaire. Health Qual Life Outcomes 2003;1:13. http://dx.doi.org/10.1186/1477-7525-1-13

8. Reda AA, Kotz D, Kocks JW, Wesseling G, van Schayck CP. Reliability and validity of the clinical COPD questionniare and chronic respiratory questionnaire. Respir Med 2010;104(11):1675-82. http://dx.doi.org/10.1016/j.rmed.2010.04.023

9. Kocks JW, Asijee GM, Tsiligianni IG, Kerstjens HA, van der Molen T. Functional status measurement in COPD: a review of available methods and their feasibility in primary care. Prim Care Respir J 2011;20(3):269-75 http://dx.doi.org/10.4104/pcrj.2011.00031

10. Jones PW, Harding G, Berry $P$, et al. Development and first validation of the COPD Assessment Test. Eur Respir J 2009;34(3):648-54. http://dx.doi.org/10.1183/09031936.00102509

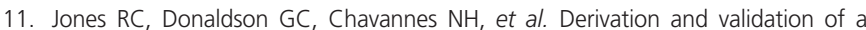
composite index of severity in chronic obstructive pulmonary disease: the DOSE Index. Am J Respir Crit Care Med 2009;180(12):1189-95. http://dx.doi.org/10.1164/rccm.200902-02710C

12. Celli BR, Cote CG, Marin JM, et al. The body-mass index, airflow obstruction, dyspnea, and exercise capacity index in chronic obstructive pulmonary disease. $\mathrm{N}$ Engl J Med 2004;350(10):1005-12. http://dx.doi.org/10.1056/NEJMoa021322

13. Puhan MA, Garcia-Aymerich J, Frey $M$, et al. Expansion of the prognostic assessment of patients with chronic obstructive pulmonary disease: the updated BODE index and the ADO index. Lancet 2009;374(9691):704-11. http://dx.doi.org/10.1016/S0140-6736(09)61301-5

14. Oga T, Tsukino M, Hajiro T, Ikeda A, Nishimura K. Predictive properties of different multidimensional staging systems in patients with chronic obstructive pulmonary disease. Int J Chron Obstruct Pulmon Dis 2011;6:521-6. http://dx.doi.org/10.2147/COPD.S24420

15. Sundh J, Janson C, Lisspers K, Stallberg B, Montgomery S. The Dyspnoea, Obstruction, Smoking, Exacerbation (DOSE) index is predictive of mortality in COPD. Prim Care Respir J 2012;21(3):295-301.

http://dx.doi.org/10.4104/pcrj.2012.00054 